Xiong, C., Lühr, H., Ma, S., Schlegel, K. (2015):

Validation of GRACE electron densities by incoherent scatter radar data and estimation of plasma scale height in the topside ionosphere.

- Advances in Space Research, 55, 8, 2048-2057.

https://doi.org/10.1016/j.asr.2014.07.022 


\title{
Validation of GRACE electron densities by incoherent scatter radar data and estimation of plasma scale height in the topside ionosphere
}

\author{
Chao Xiong ${ }^{1,2}$, Hermann Lühr ${ }^{1}$, ShuYing Ma $^{2}$, Kristian Schlegel ${ }^{3}$ \\ 1. Helmholtz Centre Potsdam, GFZ German Research Centre for Geosciences, Telegrafenberg, 14473 \\ Potsdam, Germany. \\ 2. Department of Space Physics, College of Electronic Information, Wuhan University, 430079 Wuhan, \\ China. \\ 3. Copernicus Gesellschaft e.V., 37081 Göttingen, Germany. \\ Corresponding author: Chao Xiong (Tel: +49-331-288-1884 Fax: +49-331-288-1235 \\ email:bear@gfz-potsdam.dexiongchao@whu.edu.cn)
}

\begin{abstract}
.
This paper presents an effort of using incoherent scatter radar data for validating electron density $(\mathrm{Ne})$ measurements performed by the GRACE satellites from year 2002 to 2012 . For adjusting the bias of GRACE Ne data, the observations at high latitudes from EISCAT at Troms $\varnothing$ and Svalbard, as well as two incoherent scatter radars (ISR) at mid- and low latitudes, Millstone Hill and Arecibo, are used. The adjusted GRACE $\mathrm{Ne}$ data are further compared with the observations from the four ISRs. For EISCAT observations at Troms $\varnothing$ and Svalbard the comparison results are quite consistent, yielding correlation coefficients as high as 0.92 , and an average bias value of about $3 \cdot 10^{10} \mathrm{~m}^{-3}$ is obtained. For the radars at Millstone Hill and Arecibo the results show excellent agreement, yielding correlation coefficients as high as 0.97 and an average bias of $1 \cdot 10^{10} \mathrm{~m}^{-3}$. The scale factor of adjusted GRACE $\mathrm{Ne}$ data is lower by $1 \%$ and 5\% compared to Millstone Hill and Arecibo readings, respectively. We consider these differences as within the uncertainty of radar measurements. Using the adjusted GRACE $N e$ as well as CHAMP observations during four periods of coplanar orbits between 2003 and 2008, the plasma scale heights of the topside ionosphere are determined and further compared with IRI model predictions. We find significantly larger scale heights in particular at middle and high latitudes than expected from IRI. Outstanding are the regions of the mid-latitude electron density trough.
\end{abstract}




\section{Introduction}

The GRACE (Gravity Recovery and Climate Experiment) mission, comprising of two spacecraft following each other on the same orbital track, aims primarily to measure the Earth's gravity field and its time variability with unprecedented accuracy (Tapley et al., 2004). The twin spacecraft are interconnected by a K-Band ranging (KBR) system using microwave to measure the exact separation distance and its rate of change to an accuracy of better than $0.1 \mu \mathrm{m} / \mathrm{s}$. Besides these two parameters, the change of the horizontal Total Electron Content (TEC) between the two spacecraft is also provided as a Level-1 data product of GRACE. Xiong et al. (2010) introduced a derivation of the electron density from the horizontal TEC between the two spacecraft.

The European Incoherent Scatter radar, EISCAT, is used to study the interaction between the Sun and the Earth as revealed by disturbances in the ionosphere and magnetosphere. It operates three incoherent scatter radar (ISR) systems in Northern Scandinavia, Troms $\varnothing$ and Svalbard. The incoherent scatter technique has been described in detail in many publications (e.g., Schlegel and Moorcroft, 1989; Rishbeth and Van Eyken, 1993) and will therefore not be repeated here. ISR can measure vertical electron density profiles very well, but the absolute density level needs to be calibrated by some other means, such as ionograms (Sedgemore et al., 1996). The EISCAT mainland UHF radar data is regularly calibrated by the Troms $\varnothing$ dynasonde at the EISCAT site. The antenna pointing directions and work mode of all EISCAT radars can be found e.g. in Stolle et al. (2004).

One of the most important observations from digisonde or radar is the spatial distribution of electron density in the ionosphere, especially the height profile. It usually provides the key information for ionospheric scientific studies as well as for associated practical applications. In previous studies several mathematical functions have been proposed to approximate the topside ionospheric height profiles, such as Chapman layer, exponential, parabolic or Epstein functions (Rawer et al., 1985; Di Giovanni and Radicella, 1990; Bilitza, 2001; Stankov et al., 2002; Reinisch et al., 2004). An important parameter for 
these profile functions is the ionospheric scale height, which quantifies the gradients of the electron density decrease, and intrinsically connects to ionospheric dynamics, plasma temperature and compositions (Stankov and Jakowski, 2006; Liu et al., 2008).

Compared to the ground-based digisondes and radars, the in situ measurements from satellites can provide global observations of the ionosphere. There have been a number of satellites providing electron density measurements at low-Earth orbit. A comprehensive list of relevant satellites launched before 1976 is given by Schunk and Nagy (2009) in their Table 3. In spite of the sizeable number of missions many of the pending questions were left open due to the limitations of sampling, data quality or data processing. Results from more recent missions like ROCSAT-1 (Republic of China Satellite 1), CHAMP (CHAllenging Minisatellite Payload), COSMIC (Constellation Observing System for Meteorology, Ionosphere, and Climate), and C/NOFS (Communications/Navigation Outage Forecasting System) have been reported (e.g., Su et al., 2001; Reigber et al., 2005; Rocken et al., 2000; de La Beaujardière et al., 2004; and many others).

In this study we focus on the validation of GRACE electron density measurements. In Section 2, we first introduce the derivation of the electron density from the K-Band ranging system onboard GRACE. The validation of GRACE electron density with the ISR observations from EISCAT, Millstone Hill and Arecibo is presented in Section 3. In section 4, we use the adjusted GRACE electron density as well as the CHAMP measurements to derive the plasma density scale height. A discussion and summary is given in Section 5.

\section{GRACE Electron Density Data}

The GRACE satellites, GRACE-A and GRACE-B, were launched on 17 March 2002, into a near-circular, polar (inclination: $89^{\circ}$ ) orbit with an initial altitude of about $490 \mathrm{~km}$. By the end of 2012 the altitudes of the two spacecraft have come down to about $460 \mathrm{~km}$. The local time (LT) of the orbital plane precesses 
by 4.5 min every day, taking about 161 days to cover all local times (Tapley et al., 2004). The two spacecraft follow each other at a distance of 170 220 km.

The total electron content (TEC) between the two spacecraft can be deduced from the K-Band Ranging system. When dividing the horizontal TEC by the distance between the two spacecraft the averaged electron density can be derived. In principle, electron density estimates based on radio wave measurements do not require calibration. However, there is an arbitrary bias value. For continuous segments of GRACE electron density data, the bias is constant. If a reference can be found for this continuous data series, the bias can be eliminated. Taking electron density reading from the onboard Planar Langmuir Probe (PLP) instruments of CHAMP for reference, by considering long and continuous data series, the bias in GRACE electron density data has been constrained quiet well (see Section 3 of Xiong et al., 2010). On 22 February 2010, CHAMP was turned around and flew with the boom trailing. Since then there was no electron density available anymore from CHAMP. Therefore, we had to find another way for validating the GRACE electron density data. Since GRACE is orbiting the Earth about 15 times every day, using the observation from ground-based radar when GRACE flies overhead might be a possible way for validating the GRACE electron density.

\section{Validation of GRACE electron density by ISR observations}

\subsection{EISCAT observations at Tromsø and Svalbard}

At the mid- and high-latitude trough latitudess the electron density is usually found to be lower than at other latitudes (Muldrew, 1965; Grebowsky et al., 1983; Whalen, 1987; Werner and Prölss, 1997). In the study of Xiong el al. (2013a) a minimum of electron density can be found around $\pm 60^{\circ}$ magnetic latitude (MLAT) as well as around the magnetic poles both at CHAMP and GRACE altitudes, especially during local winter (see their Fig. 1). Using ground-based observations in these low electron density regions for adjusting the GRACE $\mathrm{Ne}$ data is advantageous, since the error for bias adjustment is reduced to lowest. 
EISCAT, located at high latitude and close to the electron density trough, is considered to be suitable for GRACE electron density validation. In this study both the incoherent scatter radar (ISR) observations at Troms $\varnothing\left(69.58^{\circ} \mathrm{N}, 19.23^{\circ} \mathrm{E}\right)$ and Svalbard $\left(78.15^{\circ} \mathrm{N}, 16.03^{\circ} \mathrm{E}\right)$ are used for validation. According to GRACE's orbital characteristics the satellite passes close to a certain point on the globe twice per day on descending and ascending orbit arcs. Two successive orbits are separated by about $24^{\circ}$ in longitude, corresponding to about $900 \mathrm{~km}$ at the EISCAT radar location. Accounting for the spatial variability of electron density at high latitude we only use the radar observation when the longitudinal distance between GRACE and EISCAT radar is within $7.5^{\circ}$ (about $300 \mathrm{~km}$ ), and the time difference has been limited to within 15 min. This yielded 143 and 254 suitable GRACE overpasses from Troms $\varnothing$ and Svalbard available observations from April 2002 to December 2012.

For each of the electron density profiles from radar observations the corresponding electron density at GRACE altitude was determined in the following way. The closest (in time) radar observation (1 min average) to the GRACE overpass has been chosen for validation. From the radar-measured height profile of $\mathrm{Ne}$ we interpolated $\mathrm{Ne}$ within the range of $\pm 75 \mathrm{~km}$ centered on the GRACE cruising altitude with an exponential fit. Fig. 1 (top row) presents two electron density altitude profiles from Troms (left) and Svalbard (right) ISR observations on 29 March 2004 (Kp=3.0) and 19 April 2005 (Kp=1.3), with hmF2 $(\mathrm{NmF} 2)$ of $451 \mathrm{~km}\left(2.63 \cdot 10^{11} \mathrm{~m}^{-3}\right)$ and $263 \mathrm{~km}\left(2.20 \cdot 10^{11} \mathrm{~m}^{-3}\right)$, respectively. The electron densities of these two events show quite nice exponential profiles on the topside ionosphere (blue dashed curves). The exponential fits of $\mathrm{Ne}$ within the range of $\pm 75 \mathrm{~km}$ centered on the GRACE cruising altitude (red asterisk) are shown as red dashed curves. The standard deviations $(\sigma)$ of the exponential fits are $9.82 \%$ and $4.08 \%$ for the two events. Another two events with relatively larger $\sigma$ of $53.74 \%(K p=0.3)$ and $26.30 \%(K p=1.3)$ have also been presented in Fig. 1 (bottom row). The lager $\sigma$ of the exponential fitting implies larger fluctuation of ISR $\mathrm{Ne}$ observations around GRACE altitude.

\subsection{ISR observations at Millstone Hill and Arecibo}


During the year from 2002 to 2012 breaks of GRACE electron density time series occur quite often. In order to obtain a sufficient number of radar references for GRACE Ne adjustment, the observations from two the other two ISRs at mid- and low latitudes, Millstone Hill $\left(42.62^{\circ} \mathrm{N}, 288.51^{\circ} \mathrm{E}\right)$ and Arecibo $\left(18.34^{\circ} \mathrm{N}, 293.25^{\circ} \mathrm{E}\right)$, have also been used in this study. Since these two ISRs are at mid- and low-latitude, we use the observations when the longitudinal distance between GRACE and radar is within $10^{\circ}$, corresponding to about 850 and $1100 \mathrm{~km}$ for Millstone Hill and Arecibo, respectively. Time difference has also been limited to within 15 min. This yielded 345 and 232 suitable GRACE overpasses from Millstone Hill and Arecibo available observations from April 2002 to December 2012, respectively.

The same approach has been performed with the $N e$ observations from Millstone Hill and Arecibo, an exponential fitting to the $\mathrm{Ne}$ altitude profile within the range of $\pm 75 \mathrm{~km}$ centered on the GRACE cruising altitude. Fig. 2 presents two examples of electron density altitude profiles from Millstone Hill (left) and Arecibo (right) ISR observations on 21 May $2005(K p=0.7)$ and 08 August $2011(K p=1.0)$, with hmF2 $(\mathrm{NmF} 2)$ of $236 \mathrm{~km}\left(4.18 \cdot 10^{11} \mathrm{~m}^{-3}\right)$ and $342 \mathrm{~km}\left(5.57 \cdot 10^{11} \mathrm{~m}^{-3}\right)$, respectively. Compared to the electron density altitude profiles from EISCAT, the values of NmF2 from Millstone Hill and Arecibo are much larger and the relative fluctuations of the $N e$ observations around GRACE altitude are much smaller.

\subsection{Validation of GRACE electron density}

As presented in Fig. 1 (bottom row), the ISR Ne observations centered on the GRACE cruising altitude show relatively large fluctuations under some circumstance. The larger fluctuations of $\mathrm{Ne}$ may be caused by a low signal to noise ratio of the radar signal, increased magnetic activity, or some other effects. The more scattered $N e$ from ISR observations will definitely increase the uncertainty of the GRACE electron density validation. Fig. 3 presents the number of GRACE overpasses versus the standard deviation, $\sigma$, of the exponential fits centered on GRACE altitude. As we can see, most of the events come with $\sigma$ less than $20 \%$, although some events from EISCAT observations show large $\sigma$. In case of ISR observations from Millstone Hill and Arecibo only a few events have $\sigma$ larger than 20\%. Therefore, only the events with $\sigma$ 
less than $20 \%$ are used for the validation of GRACE electron density. This reduces the considered GRACE overpasses to 95, 193, 264, and 232 from Troms $\varnothing$, Svalbard, Millstone Hill and Arecibo, respectively.

As already introduce by Xiong et al. (2010) and Lee et al. (2011), for correcting the bias of GRACE electron density data, we first shift the biased data by setting the minimum value in each continuous dataseries from GRACE to zero. This correction indeed yields an underestimation of the actual electron density from GRACE. The next step is to use the ISR observations to adjust the underestimated GRACE data. In order to reduce the uncertainty of the adjustment caused by ISR observations, all the selected GRACE overpasses (784 in total) are further sorted into bins for each month from April 2002 to December 2014. The mean values of the differences between the ISR observations and the shifted GRACE data in each month are used for adjustment. For some months, if there is no ISR observation, the reference before or after the month will be used for the adjustment. With this technique described above, the GRACE Ne data from April 2002 to December 2012 have been adjusted.

To check the quality of the adjusted GRACE Ne data, Fig. 4 presents the comparison between the adjusted GRACE electron density and the ISR observations. The ISRs at Millstone Hill and Arecibo are quite consistent with the adjusted GRACE $N e$ data, both yield correlation coefficients as high as 0.97 . The scaling factors are close to 1 with a bias of $1 \cdot 10^{10} \mathrm{~m}^{-3}$. The standard deviations at the two sites are $2.33 \cdot 10^{10} \mathrm{~m}^{-3}$ and $3.67 \cdot 10^{10} \mathrm{~m}^{-3}$, respectively. Considering the larger background electron density at midand low-latitude, the agreement can be regarded as excellent. While the difference between EISCAT and GRACE $N e$ data is somewhat larger, with correlation coefficients of 0.91 and 0.92 for Troms $\varnothing$ and Svalbard, respectively. The standard deviations with about $3 \cdot 10^{10} \mathrm{~m}^{-3}$ are still comparably good. The lower background electron density and larger variability at high latitude is assumed to be the reason for the lower correlation coefficient between EISCAT and GRACE electron density data.

\section{Plasma Density Scale Height from CHAMP and GRACE Observations}


CHAMP and GRACE are both near circular, polar orbiting satellites, with GRACE 100-150 km higher (December 2002: $520 \mathrm{~km}$ versus $420 \mathrm{~km}$; December 2008: $480 \mathrm{~km}$ versus $330 \mathrm{~km}$ ). The precession rates of their orbital planes are different thus electron densities are generally observed at different local times. However, on four occasions their orbit planes were coplanar; that is, electron densities are observed at the same local times but at different altitudes (e.g. Bruinsma and Forbes, 2010). If CHAMP and GRACE are both flying above the peak height, hmF2, the observations from the two satellites can be used to study the vertical distribution of the electron density in the topside ionosphere.

Fig. 5 illustrates the altitude evolutions of CHAMP (black) and GRACE (blue) as well as the solar radio flux index (gray), P10.7, from 2000 to the end of 2012. The GRACE altitude is quite stable, with an initial altitude of about $490 \mathrm{~km}$ at 2002 and around $460 \mathrm{~km}$ by the end of 2012. While CHAMP decreased faster, with an altitude of about $456 \mathrm{~km}$ at 2000 and around $310 \mathrm{~km}$ by the end of 2009 . The four gray dashed lines between CHAMP and GRACE altitudes are the epochs of coplanar orbits, which centered on 10 May 2003, 07 April 2005, 12 February 2007 and 17 December 2008. Since the local time of GRACE changes by about $4.5 \mathrm{~min}$ per day, 13 days centered on each of the four coplanar events corresponding to $1 \mathrm{~h}$ in local time, have been considered for analysis. From the comparison between CHAMP and GRACE electron density measurements we estimate the plasma density scale height, $H_{p}$, under the assumption of an exponential profile of the topside ionosphere for the four epochs, as defined in equation (1):

$$
H_{p}=-\frac{h_{G}-h_{C}}{\ln \left(\frac{N e_{G}}{N e_{C}}\right)}
$$

where, $h_{C}$ and $h_{G}$ are the altitudes, $N e_{C}$ and $N e_{G}$ are the electron densities from GRACE and CHAMP, repectively.

For each of the four events, the GRACE observations are first divided into ascending and descending arcs (from pole to pole). For each arc, we find the matching part from CHAMP observations. Only orbits are 
taken into account, where the longitudinal difference (CHAMP and GRACE over the equator) is less than $10^{\circ}$, and the correlation coefficients between the $N e$ observations is larger than 0.75 . One example of such matching orbits on 18 December 2008 from CHAMP and GRACE is presented in Fig. 6. The longitudinal differences (over the equator) of the CHAMP and GRACE ascending and descending arcs are about $0.690^{\circ}$ and $0.311^{\circ}$, and the time differences of both arcs are within $2 \mathrm{~min}$. The latitudinal distributions of $\mathrm{Ne}$ observations from the two satellites are quite similar, with larger values at CHAMP altitude, yielding the correlation coefficient about 0.85 . Ne observations from both CHAMP and GRACE show a minimum at about $70^{\circ}$ MLAT, which indicate the ionopsheric trough during local winter.

Further, to get the average plasma density scale height, all observations from a coplanar event are sorted into $1^{\circ}$ wide MLAT bins. Fig. 6 presents the latitudinal profiles of $H_{p}$ derived from CHAMP and GRACE observations on dayside (black solid) and nightside (black dashed). It has to be noted that the local times are different for the four events. The scale heights are generally higher on the dayside than on the nightside (except for the events in 2003). When comparing the latitudinal difference, larger $H_{p}$ values are found at mid- and high latitudes than at the equatorial and low-latitude regions. In the previous three periods with CHAMP and GRACE observations around 1700, 1230 and $1020 \mathrm{LT}$ in the dayside, the equatorial ionization anomaly (EIA) is well developed (Ye et al., 2001; Xiong et al., 2013b). An interesting result is that $H_{p}$ is higher in the EIA trough than in the EIA crest region.

The blue curves in Fig. 7 represent the plasma density scale height derived from the latest version of the International Reference Ionosphere (IRI-2012) model (Bilitza and Reinisch, 2008; Bilitza et al., 2012). IRI offers two options for the electron density in the topside ionosphere, the corrected IRI-2001 model (Bilitza, 2004) and NeQuick model (Coïsson et al., 2006). In overall the NeQuick model shows a better representation of the topside sounder data than the corrected IRI-2001 model (Bilitza, 2009), so the NeQuick model has been used in our comparison. We first get the Ne estimate from the model for each CHAMP and GRACE observation, and then use the same assumption of an exponential profile of the topside ionosphere to derive $H_{p}$. From the results we can see that at mid- and low-latitude regions, $H_{p}$ 
derived from model is generally consistent with the observation during moderate solar activity periods in 2005 (mean P10.7=88.39 sfu); while at equatorial and low-latitude regions, $H_{p}$ derived from model is found to be smaller during higher solar activity periods in 2003 (mean P10.7=119.12 sfu), but larger during low solar activity periods in 2007 (mean P10.7=75.03 sfu) and 2008 (mean P10.7=67.14 sfu). We will provide more discussion about the differences of $H_{p}$ between the IRI-2012 model and observations in the next section.

\section{Discussion and Summary}

\subsection{Comparison between GRACE and ISR Observations}

In this study we have used the observations at high latitudes from EISCAT at Troms $\varnothing$ and Svalbard, as well as two ISRs at mid- and low latitudes from Millstone Hill and Arecibo for validation of the GRACE electron density data. Samples have been carefully selected in order to obtain reliable results. After correction for bias, the GRACE Ne data are further compared with the ISR observations. For EISCAT observations at Troms $\varnothing$ and Svalbard the comparison results are quite consistent, yielding correlation coefficients as high as 0.92 , and an average bias about $3 \cdot 10^{10} \mathrm{~m}^{-3}$ is obtained. The lower background electron density and larger variability at high latitude is assumed to be the reason for the larger scatter between EISCAT and GRACE observations.

For the radars at Millstone Hill and Arecibo, the results show excellent agreement, yielding correlation coefficients as high as 0.97 . The scale factor of adjusted GRACE Ne data is lower by $1 \%$ and $5 \%$ compared to Millstone Hill and Arecibo readings, respectively. The deviation from unity can be regarded as falling within the range of the radar uncertainties. Surprisingly, we find larger scatter, $\sigma=3.67 \cdot 10^{10} \mathrm{~m}^{-3}$, for Arecibo. In the study of Rother et al. (2010), observations from EISCAT and Arecibo are used to validate the electron temperature measurements of CHAMP. They found that for Arecibo it is important to take the local time difference between CHAMP and the radar site into account. By considering a typical diurnal variation the scatter of the differences could be reduced a lot. In our study, where we have 
set the limit to $\pm 10^{\circ}$ in longitude difference between GRACE and Millstone Hill and Arecibo sites, corresponding to $0.67 \mathrm{~h}$ in LT, the LT difference may also play an important role for the scatter.

\subsection{The Plasma Density Scale Height}

The vertical scale height derived from CHAMP and GRACE during the four coplanar events shows quite consistent results with the study of Liu et al. (2008). They used radio occultation measurements from COSMIC to derive the plasma density scale height at $400 \mathrm{~km}$. Similarly, the peak of $H_{p}$ around the dip equator during daytime is also very prominent in our three coplanar events when the EIA is well developed. For the events in 2005 and 2007 the $H_{p}$ derived from IRI-2012 model also shows prominent peak values around the dip equator on the dayside. One possibility is the $E \times B$ drift effect during daytime. The upward plasma drift caused by the daytime equatorial eastward electric field, will induce the fountain effect. As a consequence, the $F_{2}$ peak height is higher around the magnetic equator than in the EIA crest region during daytime.

For the plasma scale height on the nightside, the most prominent feature is the $H_{p}$ bulge at the midlatitude trough regions. The electron density at this region is relatively low, especially during local winter (e.g. Xiong et al., 2013a). With low background electron density the vertical profile may not follow the exponential assumption of decrease with altitude around 400-500 km (see the event in the bottom left panel of Fig. 1). An interesting result is that the $H_{p}$ bulge can also be found at the mid-latitude trough regions on the dayside during our event in December 2008. The possible reason is that the relatively low height of the $\mathrm{F}_{2}$ peak (hmF2) during the recent solar minimum could reduce the altitude at which the electron density stops following the exponential assumption to decrease in the topside ionosphere. Fig. 8 presents the geographic latitude and longitude distribution of $H_{p}$ during this event. Relatively large values of $H_{p}$ in the mid-latitude trough region can be found both on dayside and nightside.

Using CHAMP and GRACE electron density observations at 350-450 km, Lühr and Xiong (2010) reported that the IRI-2007 model overestimate the measured densities by about $50 \%$ in 2009 and by about 
$60 \%$ in 2008. To evaluate the performance of the IRI-2012 model during the recent solar minimum, Bilitza et al. (2012) has compared 30 years observations of the plasma frequency ( $f_{0} F_{2}$ ) from three European stations located in Rome/Italy (geodetic latitude: $41.8^{\circ}$, geodetic longitude: $12.5^{\circ}$ ), Ebro/Spain (geodetic latitude: $40.8^{\circ}$, geodetic longitude: $0.5^{\circ}$ ) and El Arenosillo/Spain (geodetic latitude: $37.1^{\circ}$, geodetic longitude: $353.3^{\circ}$ ). The ionosonde $\mathrm{foF}_{2}$ data are found to agree well with IRI-2012 throughout the recent solar minimum, with differences of about $20-30 \%$ and $30-40 \%$ for daytime and nighttime, respectively. By further comparing the C/NOFS electron density observations with IRI-2012 model, the difference between model and observations are found to be $74 \%$ at $400-500 \mathrm{~km}$ during $1000-1400 \mathrm{LT}$. They further suggested that by lowering the $F_{2}$ peak height or changing the topside profile shape one could obtain a good agreement with the CHAMP and GRACE measurements without changing the IRI F2-peak density $\left(\mathrm{NmF}_{2}\right)$. From our comparison of $H_{p}$, as shown in Fig. 7, during the event in 2008, the prediction of $H_{p}$ from IRI-2012 are generally higher at low-latitudes and equatorial regions, which confirm that the topside profile shape of IRI-2012 needs to be changed for better prediction during solar minimum conditions. Further studies are needed to update the IRI model with CHAMP and GRACE observations, to improve the model prediction around $300-500 \mathrm{~km}$, especially during solar minimum conditions.

In summary, using incoherent scatter radar observation it is possible to validate the GRACE electron density data. The GRACE satellites launched in March 2002 already provided more than 10 years of electron density observation, which is a valuable dataset for the study of global ionosphere climatology at about $500 \mathrm{~km}$ altitude.

\section{Acknowledgement}

We thank the Directors and the staff of EISCAT, Millstone Hill and Arecibo for providing the data and allowing the use of the MADRIGAL database. The CHAMP and GRACE missions were sponsored by 
the Space Agency of the German Aerospace Center (DLR) through funds of the Federal Ministry of Economics and Technology. The work of C. Xiong at GFZ is supported by the Alexander von Humboldt foundation through a Research Fellowship for Postdoctoral Researchers.

\section{Reference}

Bilitza, D. (2001), International reference ionosphere 2000, Radio Sci., 36(2), 261-275, doi:10.1029/2000RS002432.

Bilitza, D., Obrou, O., Adeniyi, J., Oladipo, O. (2004), Variability of foF2 in the equatorial ionosphere, Advances in Space Research 34 (9), 1901-1906, http://dx.doi.org/10.1016/j.asr.2004.08.004.

Bilitza, D., Reinisch, B.W. (2008), International Reference Ionosphere 2007: improvements and new parameters, Advances in Space Research 42 (4), 599-609, http://dx.doi.org/10.1016/j.asr.2007.07.048.

Bilitza, D. (2009), Evaluation of the IRI-2007 model options for the topside electron density, Advances in Space Research, 44, 701-706, doi:10.1016/j.asr.2009.04.036.

Bilitza, D., S.A. Brown, M.Y. Wang, R.A. Souza, P.A. Roddy (2012), Measurement and IRI model predictions during the recent solar minimum. J. Atmos. Solar Terr. Phys., 86 (2012), pp. 99-106 http://dx.doi.org/10.1016/j.jastp.201206.010.

Bruinsma, S. L., and J. M. Forbes (2010), Anomalous behavior of the thermosphere during solar minimum observed by CHAMP and GRACE, J. Geophys. Res., 115, A11323, doi:10.1029/2010JA015605.

Coïsson, P., S.M. Radicella, R. Leitinger, B. Nava (2006), Topside electron density in IRI and NeQuick: features and limitations, Adv. Space Res., 37 (5), 937-942, doi:10.1016/j.asr.2005.09.015.

de La Beaujardière, O., and the C/NOFS Science Definition Team (2004), C/NOFS: A mission to forecast scintillations, J. Atmos. Solar Terr. Phys., 66(17), 1573-1591, doi:10.1016/j.jastp.2004.07.030. 
Di Giovanni, G., Radicella, S. M., An analytical model of the electron density profile in the ionosphere, Adv. Space Res., 10, (11)27-(11)30, 1990.

Grebowsky, J.M., Taylor Jr., H.A., Lindsay, J.M. (1983), Location and source of ionospheric high latitude trough. Planet. Space Sci. 31, 99-105.

Lee, C.-K., S.-C. Han, D. Bilitza, and J.-K. Chung (2011), Validation of international reference ionosphere models using in situ measurements from GRACE K-band ranging system and CHAMP planar Langmuir probe, J. Geod., 85, 921-929, doi:10.1007/s00190-011-0442-6.

Liu, L., M. He, W. Wan, and M.-L. Zhang (2008), Topside ionospheric scale heights retrieved from Constellation Observing System for Meteorology, Ionosphere, and Climate radio occultation measurements, J. Geophys. Res., 113, A10304, doi:10.1029/2008JA013490.

Lühr, H. and Xiong, C. (2010), IRI-2007 model overestimates electron density during the 23/24 solar minimum, Geophys. Res. Lett., 37, L23101, doi:10.1029/2010GL045430.

Muldrew, D.B. (1965), F-layer ionization troughs deduced from Alouette data. J. Geophys. Res. 70, 26352650.

Rawer, K., D. Bilitza, and T. L. Gulyaeva (1985), New formulas for IRI electron density profile in the topside and middle ionosphere, Adv. Space Res., 5(7), 3-12, doi:10.1016/0273-1177(85)90347-3.

Reigber, C., Schwintzer, P., Lühr, H., Wickert, J. (2005), Earth Observation with CHAMP: Results from Three Years in Orbit, Springer, 1-628.

Reinisch, B. W., X. Huang, A. Belehaki, J. Shi, M. Zhang, and R. Ilma (2004), Modeling the IRI topside profile using scale height from ground-based ionosonde measurements, Adv. Space Res., 34, 20262031, doi:10.1016/j.asr.2004.06.012.

Rishbeth, H. and van Eyken, A. P. (1993), EISCAT: early history and the first ten years of operation, J. Atmos. Terr. Phys., 55, 525-542. 
Rocken, C., Y.-H. Kuo, W. Schreiner, D. Hunt, S. Sokolovskiy, and C. McCormick (2000), COSMIC system description, Terr. Atmos. Oceanic Sci., 11, 21-52.

Rother, M., K. Schlegel, H. Lühr, and D. Cooke (2010), Validation of CHAMP electron temperature measurements by incoherent scatter radar data, Radio Sci., 45, RS6020, doi:10.1029/2010RS004445.

Sedgemore, K. J. F., Williams, P. J. S., Jones, G. O. L., and Wright, J. W. (1996), A comparison of EISCAT and dynasonde measurements of the auroral ionosphere, Ann. Geophys., 14, 1403-1412.

Schlegel, K., and D. R. Moorcroft (1989), EISCAT as a tristatic auroral radar, J. Geophys. Res., 94(A2), 1430-1438, doi:10.1029/JA094iA02p01430.

Schunk, R. W., and A. F. Nagy (2009), Ionospheres: Physics, Plasma Physics, and Chemistry, 2nd Edition, Cambridge University Press, Cambridge, U. K.

Stankov, S. M., kutie, I. S., Jakowski, N., Electron density profiles deduced from GPS TEC, $\mathrm{O}^{+}-\mathrm{H}^{+}$ transition height and ionosonde data, Acta Geodaetica et Geophysica Hungarica, 37(2-3), 171-181, 2002.

Stankov, S. M., and N. Jakowski (2006), Topside ionospheric scale height analysis and modeling based on radio occultation measurements, J. Atmos. Sol. Terr. Phys., 68, 134-162, doi:10.1016/j.jastp.2005.10.003.

Stolle, C. and Jakowski, N. and Schlegel, K. and Rietveld, M. (2004), Comparison of high latitude electron density profiles obtained with the GPS radio occultation technique and EISCAT measurements. Annales Geophysicae, Vol. 22 (1), pp. 2015-2028.

Su, S.-Y., H. C. Yeh, and R. A. Heelis (2001), ROCSAT 1 ionospheric plasma and electrodynamics instrument observations of equatorial spread F: An early transitional scale result, J. Geophys. Res., 106(A12), 29153-29159, doi:10.1029/2001JA900109. 
Tapley, B. D., Bettadpur, S., Watkins, M., and Reigber, C. (2004), The gravity recovery and climate experiment: Mission overview and early results, Geophys. Res. Lett., 31, L09607, doi:10.1029/2004GL019920.

Whalen, J.A. (1987), Daytime F layer trough observed on a macroscopic scale. J. Geophys. Res. 92, 2571-2576.

Werner, S., Prölss, G.W. (1997), The position of the ionospheric trough as a function of local time and magnetic activity. Adv. Space Res. 20 (9), 1717-1722.

Xiong, C., J. Park, H. Lühr, C. Stolle, and S.Y. Ma (2010), Comparing plasma bubble occurrence rates at CHAMP and GRACE altitudes during high and low solar activity, Ann. Geophys., 28, 1647-1658.

Xiong, C., H. Lühr, and S.Y. Ma (2013a), The subauroral electron density trough: Comparison between satellite observations and IRI-2007 model estimates, Adv. Space Res., 51, 536-544, doi:10.1016/j.asr.2011.09.021.

Xiong, C., H. Lühr, and S.Y. Ma (2013b), The magnitude and inter-hemispheric asymmetry of equatorial ionization anomaly-based on CHAMP and GRACE observations, J. Atmos. Solar-Terr. Phys., 105-106, 160-169, doi:10.1016/j.jastp.2013.09.010.

Yeh, K. C., S. J. Franke, E. S. Andreeva, and V. E. Kunitsyn (2001), An investigation of motions of the equatorial anomaly crest, Geophys. Res. Lett., 28(24), 4517-4520, doi:10.1029/2001GL013897. 

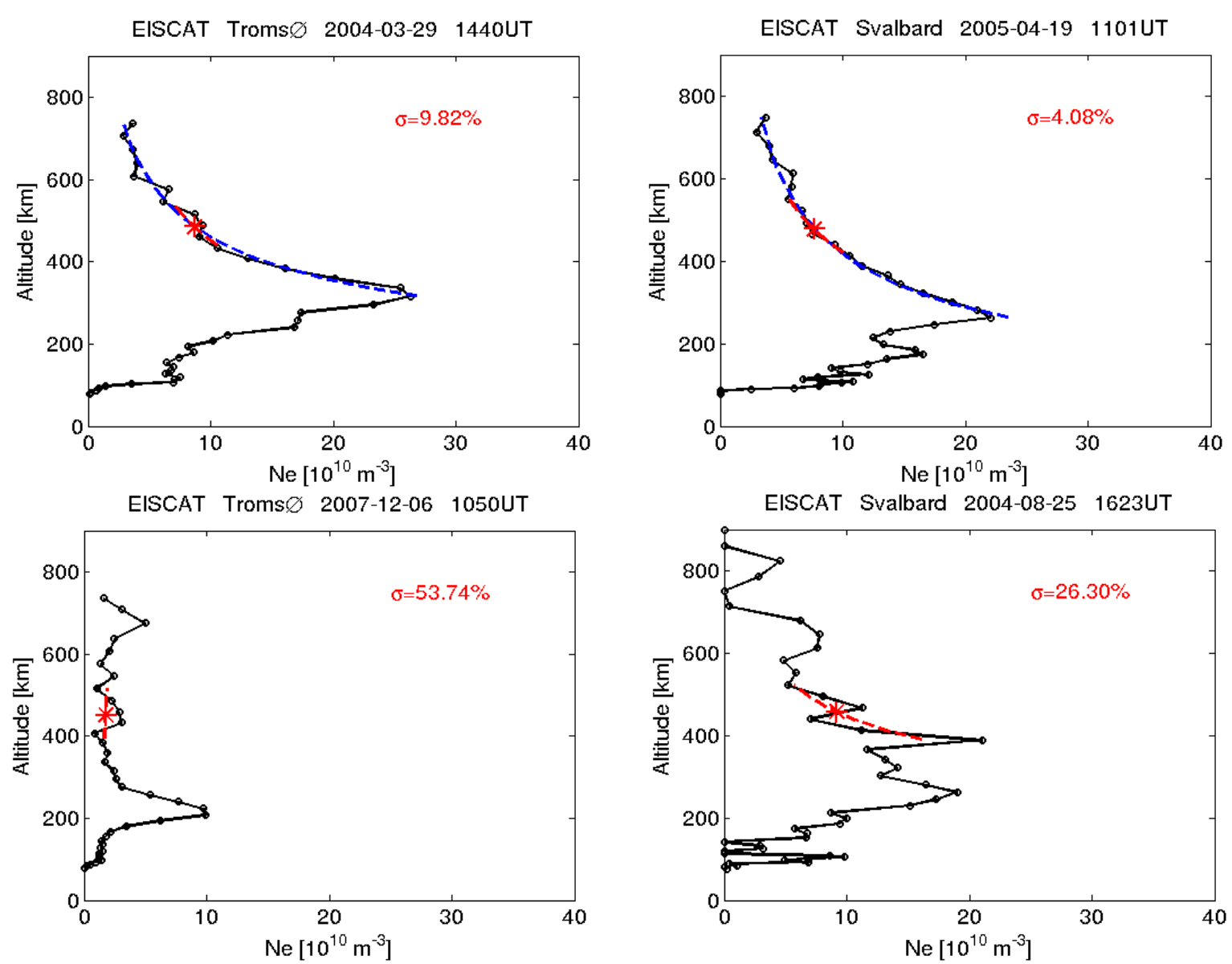

Figure 1. Electron density altitude profiles from EISCAT observations at Troms $\varnothing$ (left) and Svalbard (right). The blue dashed lines are exponential fits to the topside electron density profiles; the red dashed lines are the fits within the range of $\pm 75 \mathrm{~km}$ centered on the GRACE cruising altitude (red asterisk).
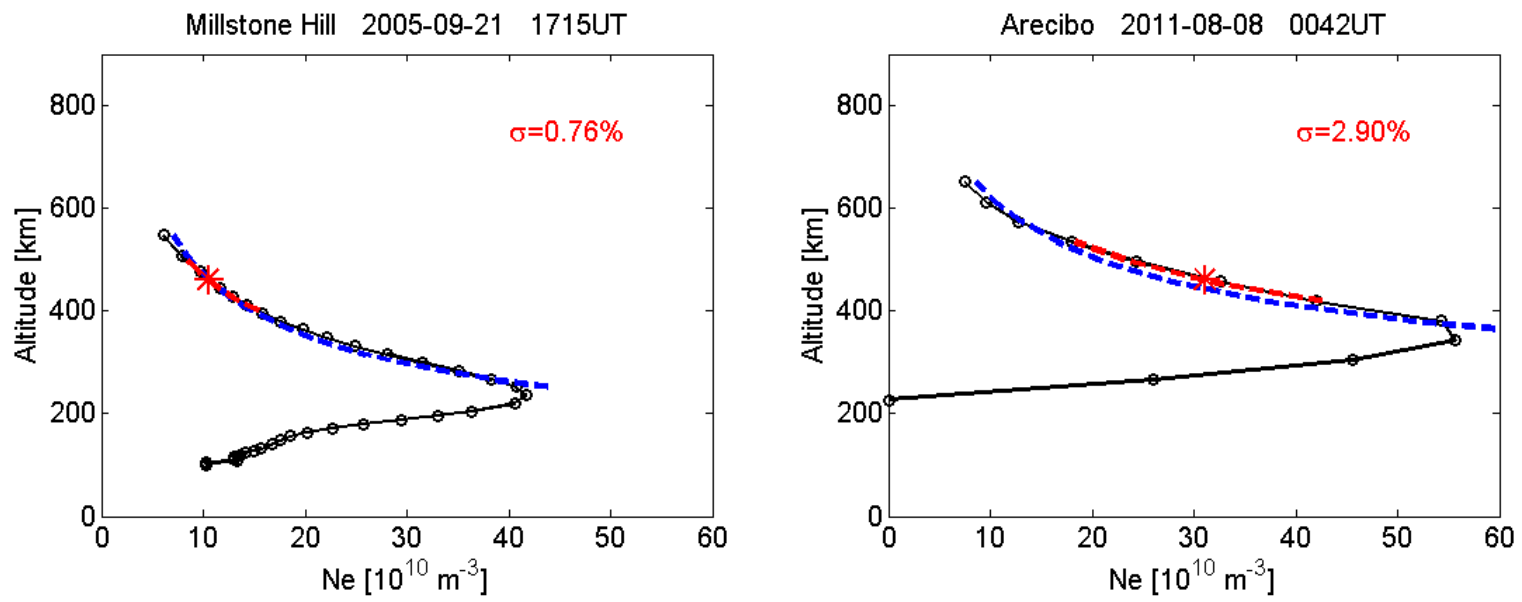

Figure 2. Same as Fig. 1, but for ISR observations from Millstone Hill (left) and Arecibo (right). 

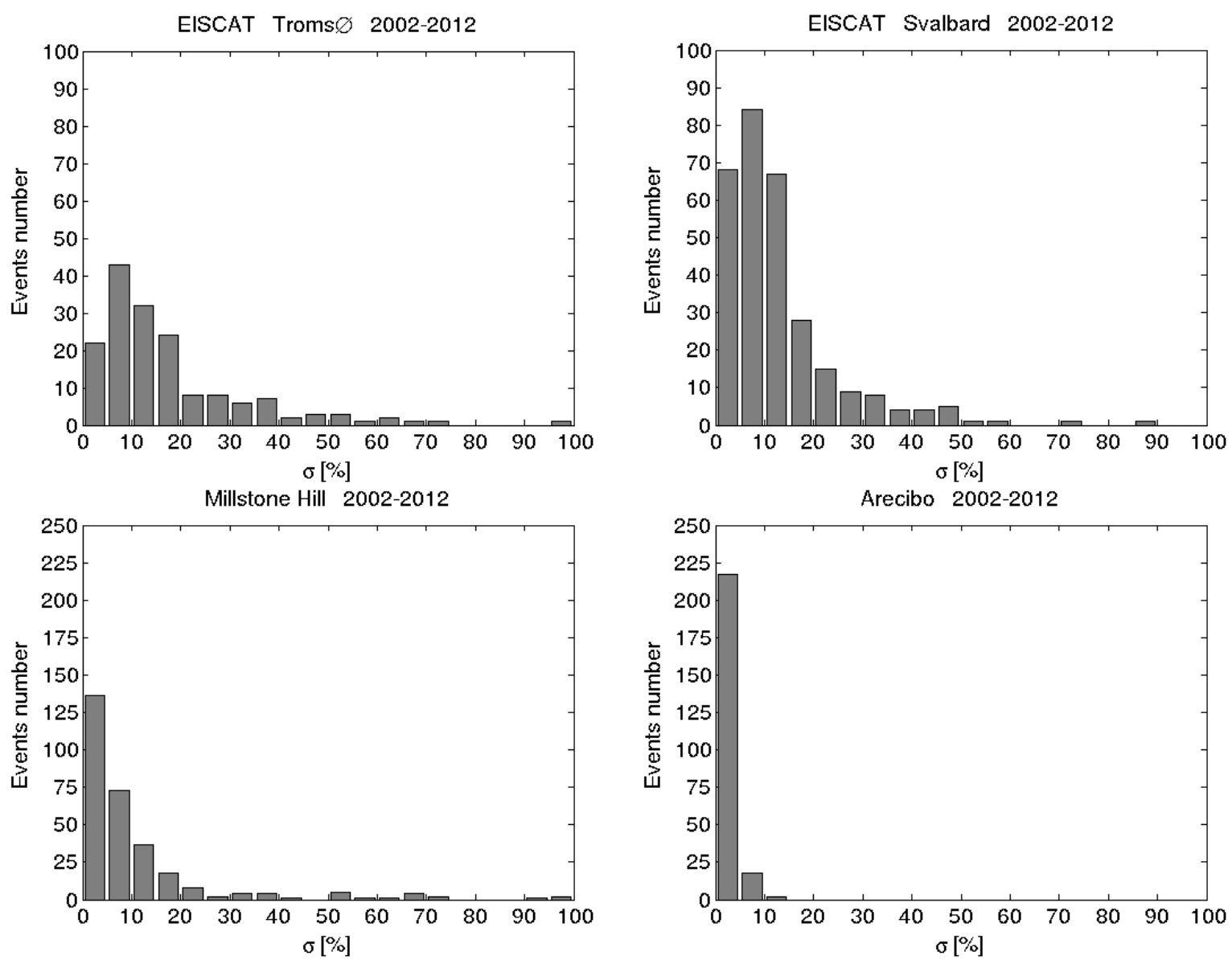

Figure 3. Number of GRACE overpasses for the four radars versus the standard deviation $(\sigma)$ between the exponential fits to $\mathrm{Ne}$ altitude profiles centered on the GRACE cruising altitude. 

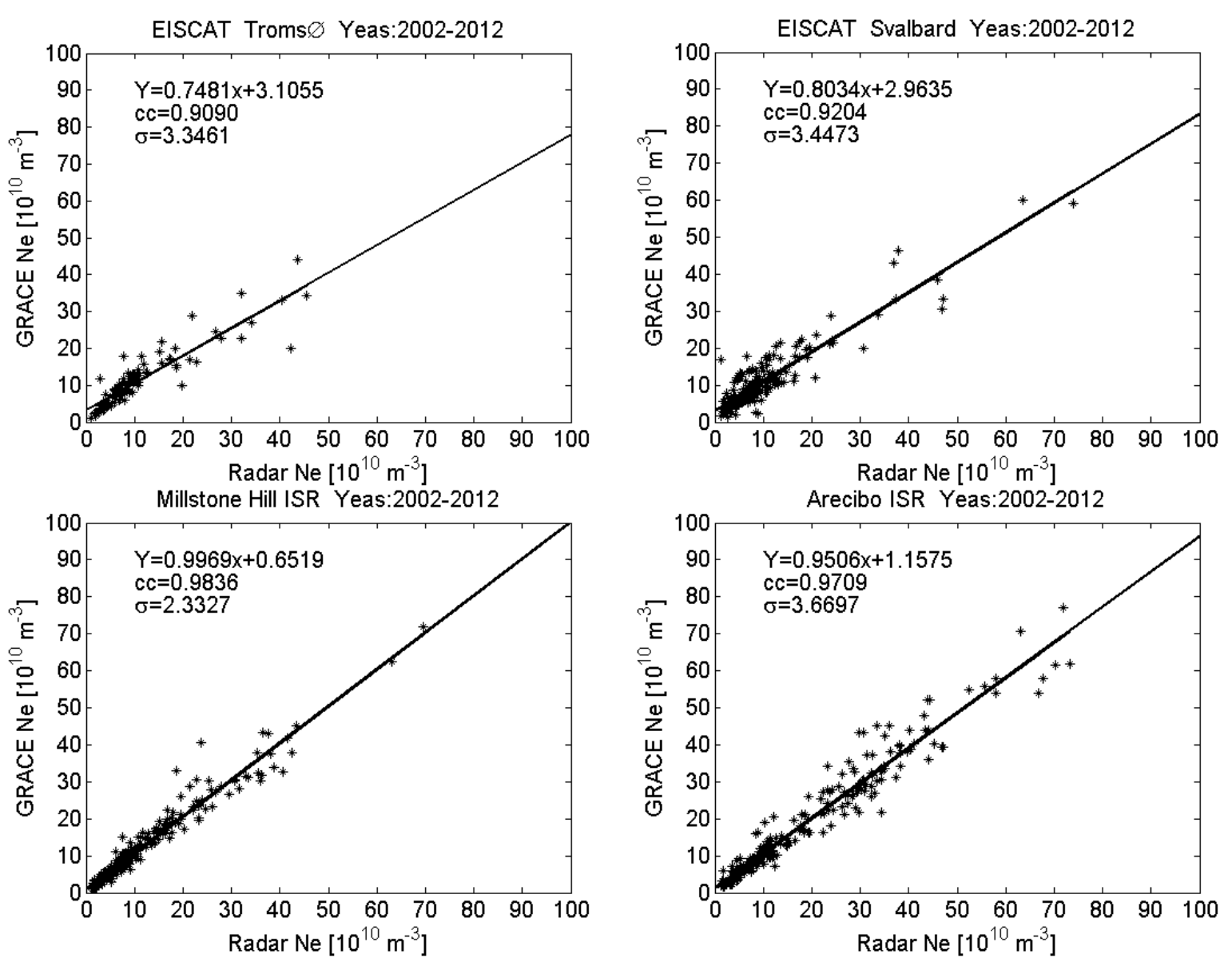

Figure 4. Comparison between the adjusted GRACE electron density and incoherent scatter radar data from EISCAT at Troms $\varnothing$ (top left) and Svalbard (top right), Millstone Hill (bottom left), as well as Arecibo (bottom right). 


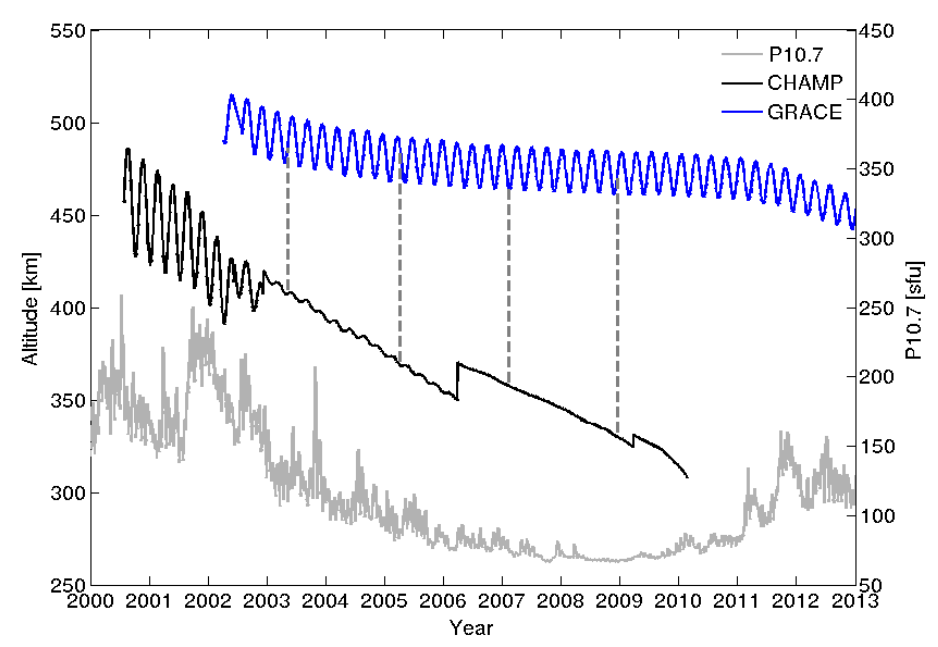

Figure 5. Evolution of the CHAMP (black) and GRACE (blue) orbit altitudes from 2000 to 2012. The vertical dashed lines indicate the four epochs of coplanar CHAMP and GRACE orbits. The grey curve shows the solar flux index, P10.7, evolution.
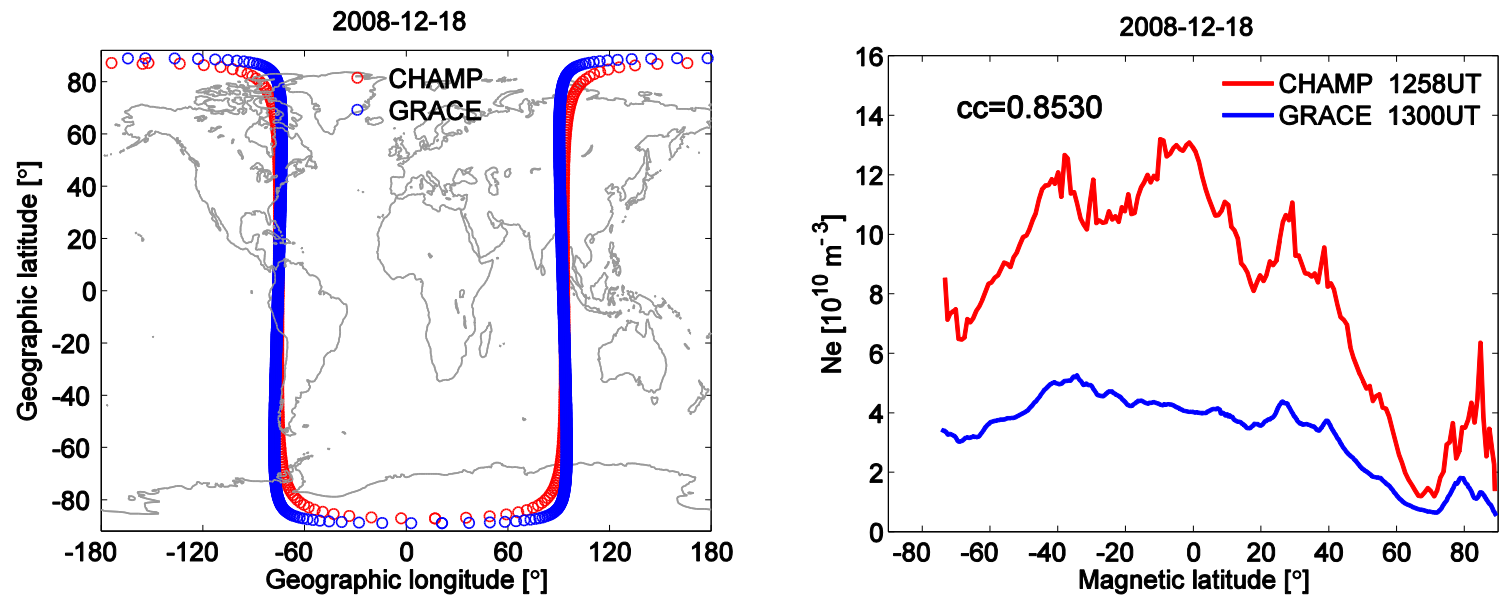

Figure 6. Trajectories of one CHAMP (red) and GRACE (blue) orbit (left) and Ne profiles of dayside half orbits (right) during the coplanar phase in 2008. 

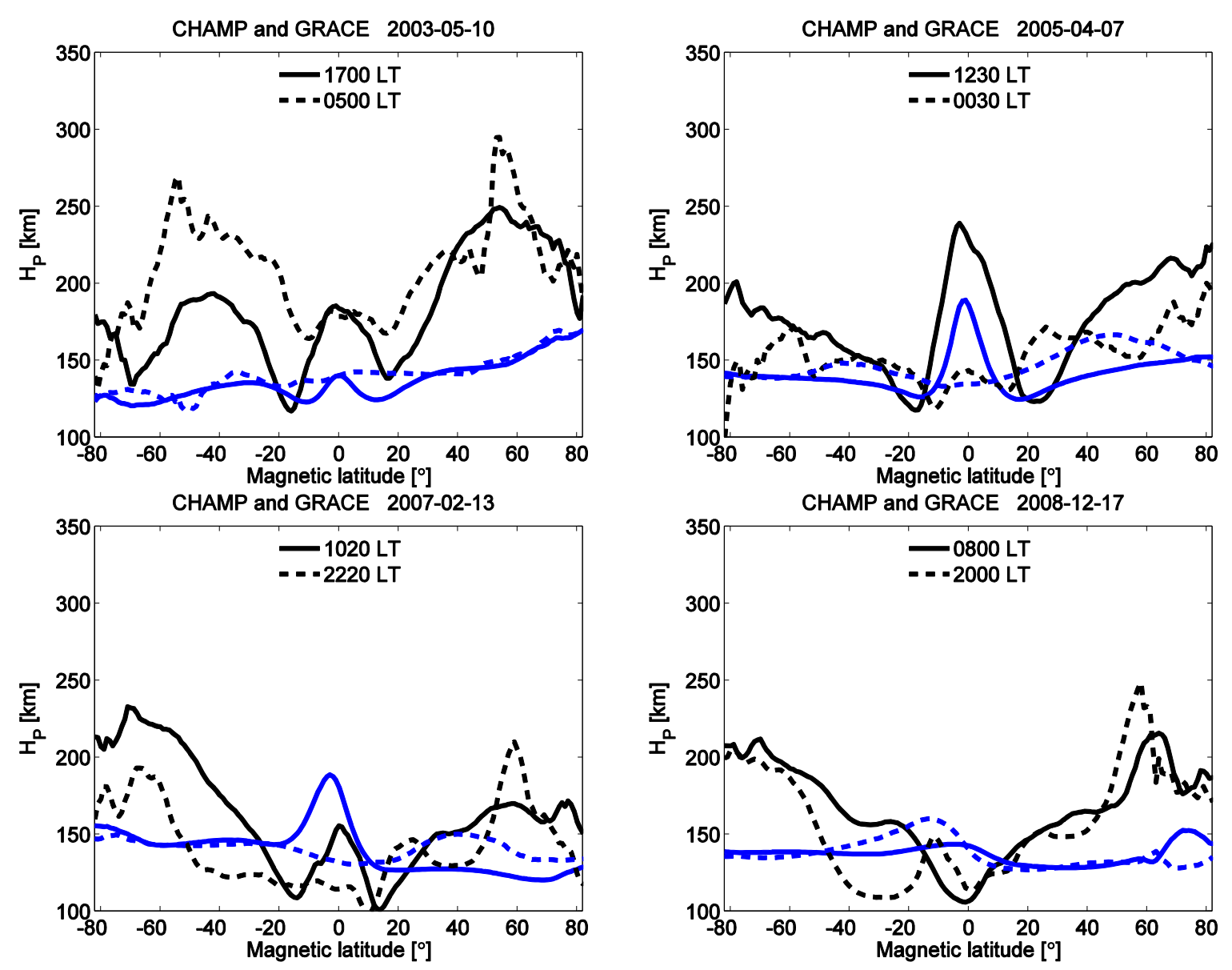

Figure 7. Latitudinal variations of $H_{p}$ on dayside (solid) and nightside (dashed) from CHAMP and GRACE comparisons (black) and concurrent IRI-2012 model estimates (blue) for the four epochs of coplanar.orbits.
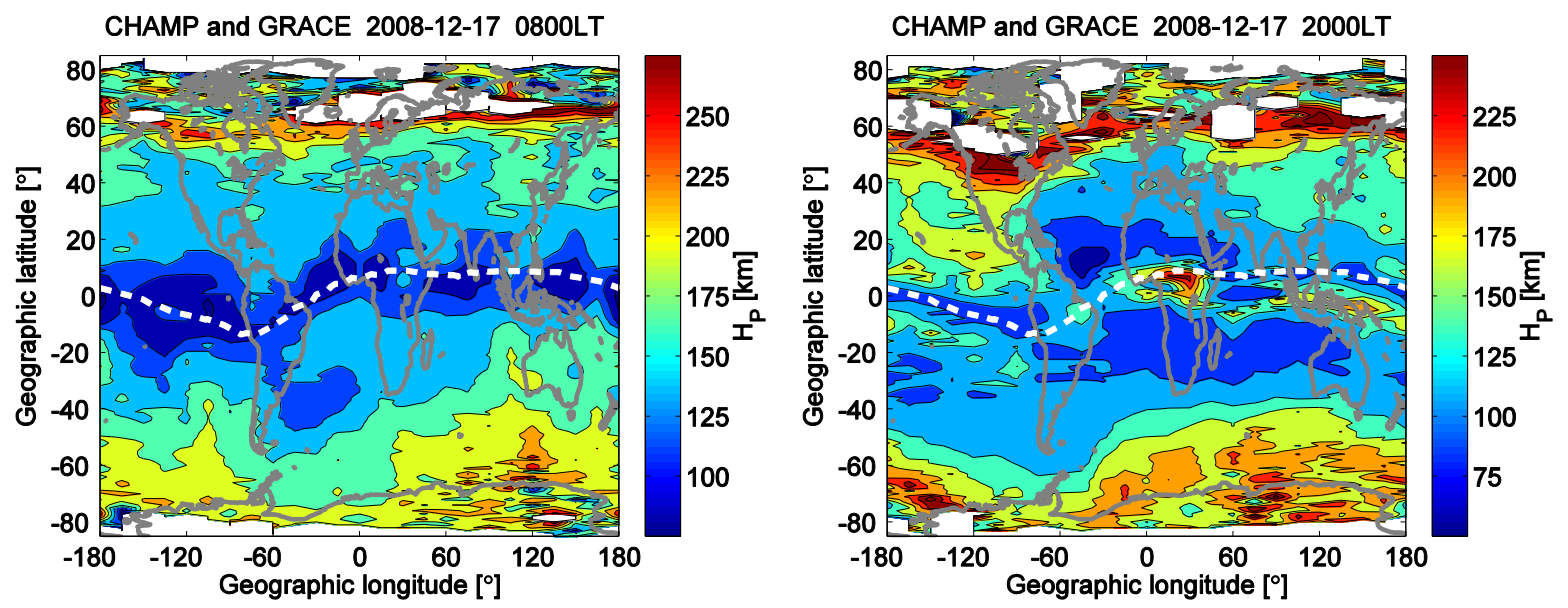

Figure 8. Latitudinal versus longitudinal variations of $H_{p}$ on dayside (left) and nightside (right) during the coplanar epoch in 2008. The white dashed lines indicate the dip equator. White patches mark regions without common data pairs. 